\title{
PEMANFAATAN LAYANAN PERPANJANGAN MASA PEMINJAMAN KOLEKSI MELALUI MEDIA SOSIAL FACEBOOK DI PERPUSTAKAAN FAKULTAS ILMU SOSIAL DAN ILMU POLITIK UNIVERSITAS GADJAH MADA YOGYAKARTA
}

\author{
Apriani Siswanti*
}

\begin{abstract}
This research aims to explore the practice of book loan renewal service through Facebook social media at the Library of Faculty of Social \&Political Sciences Gadjah Mada University. Type of this research is quantitative. Variable of this research is a single variable that is the utilization of loan renewal services through Facebook. The sampling technique in this research was accidental sampling. Samples in this research consisted of 4829 library users. Data collection methods in this research comprised observation, documentation, and interviews. Data analysis used a percentage formula and regression analysis to examine the results of the percentage of the data obtained. The results of the studyutilization of renewal service throughFacebook reached $64.43 \%$ and fine for overdue loan reached $13 \%$. A test through simple analysis indicated $r$ count $\geq 0.7230 .576$ table. So it can be said to be significant, which meant service throughFacebook was considered more beneficial. To conclude, theutilization ofloan renewal service through Facebook socialmedia was found useful.
\end{abstract}

\section{Keywords: Utilization, Library Service, Facebook, Social media}

* Alumni Universitas Islam Negeri Sunan Kalijaga

\section{A. PENDAHULUAN \\ 1. Latar Belakang}

Perpustakaan perguruan tinggi merupakan unit pelaksanaan teknis perguruan tinggi yang bersamasama dengan unit lain turut melaksanakan Tri Dharma Perguruan Tinggi dengan cara memilih, menghimpun, mengolah, merawat dan melakukan pelayanan sumber-sumber informasi kepada lembaga induk pada khususnya dan masyarakat akademis pada umumnya (Qalyubi, 2007:10).Perpustakaan perguruan tinggi adalah suatu unit kerja yang turut berperan membantu perguruan tinggi dalam melaksanakan Tri Dharma Perguruan Tinggi. Untuk mendukung kegiatan pendidikan, perpustakaan mempunyai tugas penyediaan, pengolahan dan pelayanan informasi.Sesuai dengan kedudukannya, perpustakaan berusaha memberikan pelayanan yang baik kepada seluruh civitas akademika.

Soeatminah (1992:17) menyatakan bahwa setiap orang mengharapkan pelayanan yang baik, demikian pula pemustaka. Pelayanan yang baik adalah pelayanan yang diberikan dengan cepat, tepat waktu, dan benar. Di era perkembangan teknologi informasi yang pesat, hal tersebut berimbas pada teknologi informasi yang memungkinkan setiap orang dapat mengakses sumber-sumber informasi dengan mudah, cepat, dan tepat. Menurut Siswanto-Tito (2013) dalam jurnal liquidity pesatnya perkembangan teknologi dan informasi telah menjadikan internet sebagai media komunikasi yang banyak diminati masyarakat.

Perkembangan teknologi informasi turut mempengaruhi perkembangan media sosial. Perkembangan beberapa macam media sosial antara lain youtube dan myspace yang muncul pada tahun 2003, facebook pada tahun 2004 dan twitter pada tahun 2009 (Judhita, 2011:5). Seiring dengan perkembangan media sosial, facebook masih menduduki peringkat teratas dalam penggunaan media sosial dengan total pengguna facebook telah mencapai lebih dari 1.15 miliar. Indonesia merupakan peringkat keempat negara pengguna facebook terbesar pada tahun 2014 dengan 48,8 juta pengguna yang dirilis situs bisnis.com, Selasa (15/4/2014).

Perpustakaan Fisipol UGM meningkatkan penerapan pelayanan melalui media sosial dalam upaya peningkatan mutu pelayanan agar dapat memberikan pelayanan yang cepat, mudah, dan 
akurat bagi pemustaka. Tak hanya sekedar berbagi informasi, media sosial facebook bisa menjadi salah satu sarana melakukan layanan langsung kepada pemustaka yaitu dengan bentuk perpanjangan masa peminjaman buku perpustakaan. Perpustakaan Fisipol UGM ingin mempermudah pemustaka dalam melakukan perpanjangan peminjaman koleksi melalui media sosial facebook dimana pemustaka dapat melakukan perpanjangan tanpa harus datang langsung ke perpustakaan.Dengan fasilitas facebook yang sedemikian rupa, Perpustakaan Fisipol UGM memandang media sosial facebook dari segi positifnya, bahwa layanan bisa dipermudah dengan interaksi yang bisa dilakukan tanpa memperhatikan jarak. Perpustakaan Fisipol UGM memanfaatkannya sehingga pemustaka dapat melakukan perpanjangan koleksi dari jauh tanpa harus datang ke perpustakaan. Pemustaka dapat melakukan perpanjangan tepat waktu disesuaikan dengan waktu yang dimiliki pemustaka. Dengan fasilitas yang memudahkan pemustaka seperti ini, pemustaka dapat terhindar dari denda karena dapat melakukan perpanjangan melalui facebook dari manapun pemustaka berada.

\section{Rumusan Masalah}

Berdasarkan uraian latar belakang masalah diatas, dapat dirumuskan masalah penelitian ini yaitu apakah layanan perpanjangan masa peminjaman koleksi melalui media sosial facebook di Perpustakaan Fisipol UGM bermanfaat bagi pemustaka?

\section{Tujuan dan Manfaat}

Tujuan penelitian ini adalah untuk mengetahui manfaat layanan perpanjangan masa peminjaman koleksi melalui media sosial facebook bagi pemustaka di Perpustakaan Fisipol UGM.

Sedang manfaat penelitian ini adalah sebagai umpan balik apakah pelayanan yang sedang dijalankan sudah sesuai dengan yang diharapkan pemustaka. Selain itu juga untuk memperoleh ilmu pengetahuan dan wawasan dalam pengembangan perpustakaan, ilmu perpustakaan, dan profesi perpustakaan

\section{B. TINJAUAN PUSTAKA DAN LANDASAN TEORI}

\section{Tinjauan Pustaka}

Beberapa topik penelitian yang berkenaan dengan pemanfaatan dan layanan perpustakaan telah dilakukan oleh peneliti terlebih dahulu, menurut hasil penelusuran yang dilakukan terhadap beberapa penelitian sejenis, ditemukan hasil penelitian yang memiliki kesamaan sekaligus terdapat perbedaan dengan tema yang peneliti lakukan.

Penelitian pertama, oleh Siyam Rubiyanti (2007) dengan judul "Efektivitas Pemanfaatan Koleksi di Perpustakaan Jurusan pendidikan Kimia Universitas Negeri Yogyakarta. Hasil penelitian ini menunjukkan bahwa koleksi perpustakaan sebagian besar $(56,70 \%)$ telah efektif dimanfaatkan oleh pemakai perpustakaan. Penelitian kedua oleh Yunistia Sekar Sarworini (2008) yang berjudul "Persepsi Pemustaka Terhadap Layanan Mandiri Dalam Sistem Peminjaman dan Pengembalian Koleksi di Perpustakaan Universitas Islam Negeri (UIN) Sunan Kalijaga Yogyakarta". Penelitian ini bertujuan untuk mengetahui bagaimana perpsepsi pemustaka terhadap layanan mandiri dalam sistem peminjaman dan pengembalian koleksi di perpustakaan UIN Sunan kalijaga Yogyakarta. Penelitian ketiga oleh Hasan Latif (2011) dengan judul "Efektivitas Pelayanan Pengembalian Mandiri dengan Menggunakan Book Drop Bagi Pemustaka di Perpustakaan UIN Sunan Kalijaga Yogyakarta". Penelitian ini memperoleh kesimpulan bahwa efektivitas layanan pengembalian mandiri menggunakan book drop bagi pemustaka di perpustakaan UIN Sunan Kalijaga Yogyakarta berada pada rata-rata nilai baik.

\section{Landasan teori}

a. Pemanfaatan Perpustakaan

Pemanfaatan berasal dari kata dasar manfaat yang berarti guna, faedah, adapun memanfaatkan berarti membuat sesuatu menjadi berguna sementara pemanfaatan adalah hal, cara, hasil kerja memanfaatkan (Badudu, 1994:859).

\section{b. Perpustakaan Perguruan Tinggi}

Perpustakaan perguruan tinggi merupakan unit pelaksanaan teknis perguruan tinggi yang bersama-sama dengan unit lain turut melaksanakan Tri Dharma Perguruan Tinggi dengan cara memilih, menghimpun, mengolah, merawat dan melakukan pelayanan sumbersumber informasi kepada lembaga induk pada khususnya dan masyarakat akademis pada umumnya (Qalyubi, 2007:10). 


\section{c. Layanan Perpustakaan}

Menurut Rahayuningsih (2007: 85) Layanan pengguna adalah salah satu kegiatan pokok perpustakaan. Layanan pengguna menjadi tolak ukur keberhasilan sebuah perpustakaan. Perpustakaan akan dinilai baik secara keseluruhan oleh pengguna, jika mampu memberikan layanan yang terbaik, dan dinilai buruk secara keseluruhan, jika layanan yang diberikan buruk. Kegiatan layanan adalah kegiatan yang kegiatan yang mempertemukan langsung antara petugas dengan pengguna perpustakaan, sehingga penilaian pengguna akan muncul ketika layanan tersebut dilangsungkan. Layanan yang diberikan kepada pengguna mencakup koleksi, fasilitas dan jasa perpustakaan.

\section{Layanan Sirkulasi}

Layanan sirkulasi di perpustakaan merupakan salah satu kegiatan yang berkaitan dengan pengguna perpustakaan. Menurut Rahayu (2011:2.2) Layanan sirkulasi adalah suatu pekerjaan, tugas, kegiatan yang berhubungan dengan pemanfaatan koleksi perpustakaan oleh pemakai perpustakaan.

\section{Perpanjangan Masa Peminjaman}

Perpanjangan perihal memperpanjang: mengurus, artinya perpanjangan adalah mengurus sesuatu agar menjadi lebih lama (Kamus Besar Bahasa Indonesia, 2005: 645). Dalam artian waktunya yang diperpanjang. Sedang masa yang dimaksudkan disini adalah waktu; ketika; saat (Kamus Besar Bahasa Indonesia, 2005: 561). Dalam hal ini dapat diartikan bahwa masa adalah waktu yang diperpanjang. Dalam layanan perpustakaan kegiatan perpanjangan masa peminjaman adalah kegiatan pencatatan kembali koleksi yang pernah dipinjam sesuai kurun waktu yang ditentukan (Rahayuningsih, 2007:96).

\section{d. Media Sosial Facebook}

Andreas Kaplan dan Michael Haenlein dalam Miranda (2010) mendefinisakan media sosial sebagai sebuah kelompok aplikasi berbasis internet yang membangun di atas dasar ideologi dan teknologi Web 2.0, dan yang memungkinkan penciptaan dan pertukaran. Juditha (2011:5) menjelaskan bahwa situs jejaring sosial merupakan sebuah web berbasis pelayanan yang memungkinkan penggunaanya untuk membuat profil, melihat daftar pengguna yang tersedia, serta mengundang atau menerima teman untuk bergabung dalam situs tersebut.
Menurut Golder dalam Hopkins (2012:133) Facebook diluncurkan pada bulan Februari 2004, awalnya untuk menghubungkan mahasiswa Haward College, dimana pengguna dapat mengisi halaman profil mereka sendiri dengan informasi pribadi dan membangun pertemanan. Pengguna dapat mengirim pesan satu sama lain, bergabung dengan kelompok sosial dan berbagi foto, video dan pesan publik singkat pada papan buletin yang disebut dinding. Facebook telah menjadi top situs jejaring sosial dengan pengguna aktif harian rata-rata 844 juta untuk September 2014 (facebook newsroom, 2014).

\section{METODE PENELITIAN}

Dalam penelitian ini, peneliti menggunakan metode deskriptif karena sifatnya menjelaskan atau mendeskripsikan fenomena yang diteliti, pendekatannya yang digunakan adalah dengan metode kuantitatif. Penelitian dilaksanakan di Perpustakaan FISIPOL UGM pada bulan September 2015.

\section{Subjek dan Objek Penelitian}

Pada penelitian ini yang menjadi subjek penelitian adalah pengguna layanan perpanjangan masa peminjaman koleksi melalui facebook. Objek dari penelitian ini adalah pemanfaatan layanan perpanjangan melaluifacebook.

\section{Populasi dan Sampel}

Populasi dalam penelitian ini berjumlah 4.829 pengguna yang berasal dari jumlah anggota di perpustakaan FISIPOL UGM. Teknik pengambilan sampel yang digunakan dalam penelitian ini adalah accidental sampling bahwa semua pengguna bisa menjadi anggota sampel.

\section{Metode Pengumpulan Data}

Menurut Sugiyono (2013: 224) metode pengumpulan data merupakan langkah yang paling strategis dalam penelitian, karena tujuan utama dari penelitian adalah mendapatkan data.

\section{Dokumentasi}

Menurut Arikunto (2013:274) dokumentasi adalah suatu usaha untuk mencari data-data mengenai hal-hal atau variabel yang berupa catatan, transkip, buku, surat kabar, majalah, prasasti, notulen rapat, agenda, dan sebagainya. Metode ini digunakan untuk melihat fakta-fakta yang terkait dengan objek penelitian yang sedang diteliti. 


\section{Observasi}

penelitian ini menggunakan metode observasi nonpartisipan, yaitu penulis melakukan pengamatan terhadap layanan pengembalian pada facebook tetapi tidak terlibat langsung dalam kegiatan layanannya.

\section{Wawancara}

Dalam penelitian ini digunakan wawancara tidak terstuktur, yaitu wawancara yang bebas dimana peneliti tidak menggunakan pedoman wawancara yang telah tersusun secara sistematis dan lengkap untuk pengumpulan datanya (Sugiyono,2013:140).

\section{Variabel Penelitian}

Penelitian ini menggunakan variabel tunggal karena hanya ada satu titik perhatian yaitu pemanfaatan layanan perpanjangan peminjaman melalui facebook di Perpustakaan Fisipol UGM.

\section{Analisis Data}

Menurut Sudijono (2003: 43) rumus yang digunakan adalah rumus persentase sebagai berikut:

$$
P=\frac{f}{n} \times 100 \%
$$

Keterangan:

$P$ : Angka Persentase

f : frekuensi yang sedang dicari persentasenya

$\mathrm{n}$ : number of cases

Dalam penelitian ini, digunakan uji analisis regresi sederhana untuk menguji hasil persentase data yang diperoleh.Tujuan dari analisis ini adalah untuk memperkirakan atau menaksir besarnya efek kuantitatif dari suatu kejadian terhadap kejadian lain (Sulaiman, 2004:2).

\section{HASIL DAN PEMBAHASAN}

Pada tahun 2014, terdapat 4.829 transaksi peminjaman koleksi.Berdasarkandata pada tahun 2014 selanjutnya dibuat sebaran data peminjam untuk setiap bulannya. Adapun sebaran data peminjam di setiap bulannya sebagai berikut:
Tabel 1. Sebaran Data Peminjam Setiap Bulannya di Perpustakaan FISIPOL UGM

\begin{tabular}{clc}
\hline No. & Nama Bulan & Banyak Pemustaka \\
\hline 1. & Januari & 658 \\
2. & Februari & 350 \\
3. & Maret & 369 \\
4. & April & 432 \\
5. & Mei & 456 \\
6. & Juni & 360 \\
7. & Juli & 266 \\
8. & Agustus & 254 \\
9. & September & 350 \\
10. & Oktober & 355 \\
11. & November & 436 \\
12. & Desember & 543 \\
Jumlah & & 4829 \\
\hline
\end{tabular}

Sumber: Dokumentasi SIPUS Perpustakaan FISIPOL UGM

Peneliti membatasi kajian penelitian pada data pemustaka layanan perpanjangan melalui facebook pada tahun 2014. Pembatasan ini dilakukan penulis dengan alasan untuk mempersempit objek yang akan diteliti. Sedangkan alasan peneliti untuk meneliti data pemustaka layanan pada tahun 2014 adalah karena tahun tersebut merupakan tahun paling baru untuk mencari data selama satu tahun dan peneliti memiliki asumsi bahwa pemustaka banyak melakukan perpanjangan melalui media sosial facebook pada tahun 2014.

Pemustaka yang menggunakan layanan perpanjangan masa peminjaman koleksi melalui media sosial facebook pada tahun 2014 sebanyak 3.113 pemustaka. Jumlah tersebut berdasarkan data pemustaka dari dinding fanpage sebanyak 78 kiriman pada tahun 2014, pesan pribadi pada akun facebook perpustakaan sebanyak 858 kiriman pesan, dan pada dinding akun facebook perpustakaan itu sendiri sebanyak 2.177 kiriman. Sedang Pada tahun 2014, terdapat 630 pemustaka yang dikenai denda karena terlambat mengembalikan koleksi yang dipinjamnya. Data pada tahun 2014 selanjutnya dibuat persentase untuk setiap bulannya dan kemudian akan dibuat persentase denda secara keseluruhan pada tahun 2014. Berikut ini tabel perbandingan data layanan dengan denda: 
Tabel 2. Perbandingan Data Layanan Facebook dan denda

\begin{tabular}{clcc}
\hline No. & Nama Bulan & Layanan Facebook & Denda \\
\hline 1. & Januari & 285 & 87 \\
2. & Februari & 199 & 65 \\
3. & Maret & 286 & 46 \\
4. & April & 328 & 49 \\
5. & Mei & 316 & 67 \\
6. & Juni & 257 & 35 \\
7. & Juli & 181 & 43 \\
8. & Agustus & 139 & 33 \\
9. & September & 245 & 38 \\
10. & Oktober & 256 & 67 \\
11. & November & 295 & 44 \\
12. & Desember & 326 & 56 \\
Jumlah & 3113 & 630 \\
\hline
\end{tabular}

Selanjutnya dikelompokkan dalam sebaran penggunaan pada setiap bulannya dan dihitung persentasenya. Berikut ini contoh penghitungannya:

Tabel 3. Data Pemustaka Bulan Januari

\begin{tabular}{clc}
\hline No. & \multicolumn{1}{c}{ Media Penyampaian } & Banyak pemustaka \\
\hline 1. & Dinding fanpage & 3 \\
2. & Pesan pribadi & 31 \\
3. & Dinding facebook & 251 \\
Jumlah & 285 \\
\hline
\end{tabular}

Sumber: dokumentasi akun facebook Perpustakaan FISIPOL UGM

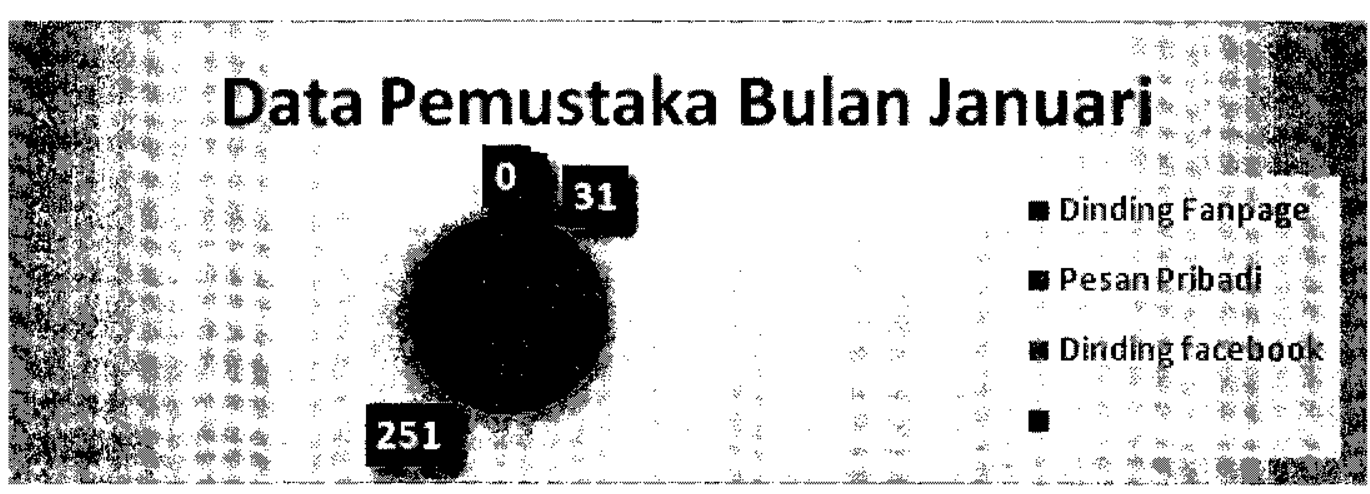

Gambar 1. Data Pemustaka Bulan Januari

Berdasarkan data diatas, maka dapat dihitung pemanfaatan layanan pada bulan Januari sebagai berikut:

Peminjaman tahun $2014(\mathrm{n})=4.829$ pemustaka

Pemustaka pada bulan januari $(\mathrm{f})=285$ pemustaka

Maka angka pemanfaatan adalah

$$
I=\frac{285}{4.829} \times 100 \%=5,90 \%
$$

Sedang persentase untuk denda sebagai berikut:

Data Peminjaman tahun 2014 dan Data Denda Bulan Januari 2014

\begin{tabular}{lc}
\hline Peminjaman tahun 2014 (n) & 4.829 pemustaka \\
\hline Denda bulan januari (f) & 87 pemustaka \\
\hline Sumber: Dokumentasi SIPUS Perpustakan FISIPOL UGM
\end{tabular}


Maka angka persentase denda bulan januari adalah

$$
P=\frac{87}{4.829} \times 100 \%=1.80 \%
$$

Berdasarkan hasil persentase dari masing-masing bulan maka pemanfaatan layanan perpanjangan masa peminjaman melalui media sosial facebook di Perpustakaan FISIPOL UGM diperoleh data penggunaan dalam kurun waktu satu tahun pada tahun 2014 adalah sebagai berikut

Tabel 4. Perbandingan Hasil persentase Pemanfaatan Layanan dan Denda

\begin{tabular}{clll}
\hline No. & \multicolumn{2}{c}{ Layanan dengan facebook } & Denda \\
\hline 1. & Januari 5,90 & & 1,80 \\
2. & Februari & 4,12 & 1,34 \\
3. & Maret & 5,92 & 0,95 \\
4. & April & 6,80 & 1,01 \\
5. & Mei & 6,54 & 1,38 \\
6. & Juni & 5,32 & 0,72 \\
7. & Juli & 3,74 & 0,68 \\
8. & Agustus & 2,87 & 0,89 \\
9. & September & 5,07 & 0,79 \\
10. & Oktober & 5,30 & 1,38 \\
11. & November & 6,10 & 0,91 \\
12. & Desember & 6,75 & 1,15 \\
& Jumlah & 64,43 & 13 \\
\hline
\end{tabular}

Data primer diolah 2014

Perbandingan hasil persentase diatas, dapat dilihat pada setiap bulan padatahun 2014 bahwa tingkat pemanfaatan dari layanan perpanjangan dengan facebook lebih besar dibanding persentase denda pada setiap bulannya. Begitu juga dengan jumlah total persentasenya, layanan dengan facebook mempunyai total $64,43 \%$ dan denda dengan total $13 \%$. Hal ini dapat dikatakan bahwa layanan perpanjangan dengan facebook bermanfaat dikarenakan dapat menekan jumlah denda pada setiap bulannya.

Selanjutnya dilakukan penghitungan manfaat penggunaan layanan perpanjangan masa peminjaman melalui facebook di Perpustakaan FISIPOL UGM pada tahun 2014 dengan menggunakan rumus regresi linier sederhana menggunakan program SPSS version 16 for windows.

Tabel 5. Hasil Regresi Linier Sederhana

Model Summary

\begin{tabular}{|c|c|c|c|c|}
\hline Model & $\mathrm{R}$ & R Square & $\begin{array}{c}\text { Adjusted R } \\
\text { Square }\end{array}$ & $\begin{array}{l}\text { Std. Error of the } \\
\text { Estimate }\end{array}$ \\
\hline$\sqrt{1}$ & $.723^{\mathrm{a}}$ & .523 & .475 & 82.06977 \\
\hline
\end{tabular}

$\mathrm{r}$ hitung $\leq / \geq \mathrm{r}$ tabel sama artinya dengan signifikan atau tidak. Jika $r$ hitung $\geq r$ tabel maka dapat dikatakan signifikan, akan tetapi jika $r$ hitung $\leq \mathrm{r}$ tabel maka dapat dikatakan tidak signifikan. Signifikan berarti layanan dengan menggunakan facebook lebih bermanfaat daripada layanan manual.

Berdasarkan tabel di atas, menunjukkan bahwa $\mathrm{r}$ hitung memiliki nilai sebesar 0,723. Untuk jumlah $\mathrm{n}=12$ data yang diinput, dengan taraf signifikansi 5\% r tabel menunjukkan angka 0,576 . Berarti $0,723 \geq 0,576$ jadi nilai $r$ hitung lebih besar daripada $r$ tabel, sehingga nilai tersebut signifikan. Yang artinya dapat dikatakan bahwa layanan dengan menggunakan facebook lebih bermanfaat daripada layanan manual.

\section{E. KESIMPULAN}

Berdasarkan hasil dan pembahasan penelitian di atas, maka dapat disimpulkan sebagai berikut:

Sedangkan untuk hasil analisis regresi antara layanan facebook dengan peminjaman manual, didapatkan nilai $r$ hitung memiliki 
nilai sebesar 0,723.Dengan taraf signifikansi $5 \%$, untuk 12 data yang diinput nilai pada $\mathrm{r}$ tabel 0,576 . Dengan demikian nilai 0,723 tersebut lebih besar dari $r$ tabel 0,576 .Maka nilai tersebut bernilai positif, menunjukkan adanya manfaat atau pemanfaatan. Artinya, dari hasil nilai yang diolah maka dapat dinyatakan bahwa layanan perpanjangan masa peminjaman koleksi melalui media sosial facebook dapat dikategorikan bermanfaat.

\section{Saran}

Berdasarkan simpulan diatas, maka penulis dapat memberikan saran sebagai berikut:

1. Perpustakaan FISIPOL UGM terus meningkatkan layanan kepada pemustaka nya sehigga layanan melalui media sosial facebook dapat membantu untuk mengurangi denda dan bahkan nantinya dapat menghilangkan denda yang dikenakan kepada pemustaka.

2. Selain itu diadakannya rekapitulasi penghitungan dalam setiap tahunnya, sehingga dapat diketahui perkembangannya dan dapat menjadi bahan evaluasi Perpustakaan FISIPOL UGM dalam meningkatkan layanan kepada pemustaka.

\section{DAFTAR PUSTAKA}

Arikunto, Suharsimi. 2013. Prosedur Penelitian : Suatu Pendekatan Praktik. Jakarta: Rineka Cipta.

Badudu.1994. Kamus Umum Bahasa Indonesia. Jakarta: Pustaka Sinar Harapan.

Hasan Latif. 2011. "Efektivitas Pelayanan Pengembalian Mandiri dengan Mengggunakan Book Drop Bagi Pemustaka di Perpustakaan UIN Sunan Kalijaga Yogyakarta". (Skripsi). Jurusan Ilmu Perpustakaan dan Informasi Fakultas Adab, UIN Sunan Kalijaga Yogyakarta.

Hopkins, John. 2012. "Can Facebook Be an Effective Mechanism For Generating Growth and Value in Small Bussiness?". Journal of Systems and Information Technology Vol. 14 No. 2.Tahun 2012. Diunduh Pada 13 Januari 2015
Judhita, Christiany. 2011. "Hubungan Penggunaan Situs Jejaring Sosial Facebook Terhadap Perilaku Remaja di Kota Makassar". Jurnal Penelitian IPTEK-KOM, Vol.13, No.1. Tahun 2011. Diunduh Pada 18 Juli 2014.

Kamus Besar Bahasa Indonesia. 2005. Jakarta: Balai Pustaka.

Miranda, Giovanna F. 2010. "How the New Web Generations are Changing Library and Information Services". Meical Reference Service Quarterly, Tahun 2010, hlm.132-135.

Qalyubi, Syihabuddin dkk. 2007. Dasar-Dasar Ilmu Perpustakaan dan Informasi. Yogyakarta: Jurusan Ilmu Perpustakaan dan Informasi (IPI) Fakultas Adab UIN Sunan Kalijaga

Rahayu, Lisda dan Kiemas, Ramatun Anggraini. 2012. Pelayanan Bahan Pustaka. Jakarta: Universitas Terbuka.

Rahayuningsih, F. 2007. Pengelolaan Perpustakaan. Yogyakarta: Graha Ilmu.

Siyam Rubiyanti. 2007. "Efektivitas Pemanfaatan Koleksi di Perpustakaan Jurusan Pendidikan Kimia Universitas Negeri Yogyakarta". (Skripsi). Jurusan Ilmu Perpustakaan dan Informasi Fakultas Adab, UIN Sunan Kalijaga Yogyakarta.

Soeatminah.1992. Perpustakaan Kepustakawanan dan Pustakawan. Yogyakarta: Kanisius.

Sudijono, Anas. 2003. Pengantar Statistika Pendidikan. Jakarta: Raja Grafindo Persada.

Sugiyono. 2013. Metode Penelitian Kuantitatif Kualitatifdan $R \& D$. Bandung: Alfabeta

Sulaiman, Wahid. 2004. Analisis Regresi Menggunakan SPSS. Yogyakarta: Penerbit Andi.

Yunistia Sekar Sarworini. 2008. "Persepsi Mahasiswa Terhadap Layanan Mandiri dalam Sistem Peminjaman dan Pengembalian Koleksi di Perpustakaan Universitas Islam Negeri (UIN) Sunan Kalijaga Yogyakarta". (Skripsi). Jurusan Ilmu Perpustakaan dan Informasi Fakultas Adab, UIN Sunan Kalijaga Yogyakarta. 